\title{
Knowledge, attitudes and perceptions of sexual and reproductive health rights among undergraduates in state universities in Sri Lanka
}

Upuli Perera ( $\nabla$ tauapp100@gmail.com )

Ministry of Health

Chrishantha Abeysena

University of Kelaniya

\section{Research Article}

Keywords: attitudes, knowledge, reproductive health, sexual, rights, undergraduates

Posted Date: March 7th, 2022

DOI: https://doi.org/10.21203/rs.3.rs-1364774/v2

License: (c) (i) This work is licensed under a Creative Commons Attribution 4.0 International License.

Read Full License 


\section{Abstract}

Introduction: Sexual and Reproductive Health Rights (SRHR) are universal. The objective was to describe the knowledge and attitudes and explore the perceptions regarding SRHR among undergraduates.

Methods: A cross sectional study was conducted among 1575 undergraduates using stratified cluster sampling of the selected universities. A pre-tested self-administered questionnaire was administered to assess knowledge and attitudes on SRHR. In addition, focus group discussions were conducted to explore perceptions and attitudes regarding SRHR.

Three hundred and eighty-five $(24.4 \%, \mathrm{n}=385)$ undergraduates had good knowledge, $604(38.3 \%)$ had satisfactory knowledge and $586(37.2 \%)$ had poor knowledge on SRHR. Males and undergraduates who had studied in bioscience stream had better knowledge than the other categories $(p<0.001)$. Majority of undergraduates $(93.4 \%, n=1463)$ agreed with the statement aimed at equal say among both men and women in sexual relationships, $1234(78.8 \%)$ agreed that a woman has a right to refuse sex with her male partner anytime she wants and $511(32.7 \%)$ said women should be submissive to men. Only a very few $(3.1 \%, n=48)$ thought that the child-care would-be women's sole response. School education, law, media and culture were identified as being related to the protection and violations of rights. Suggestions were made for the improvement of SRRs including strengthening of education and proper implementation of law.

Conclusion: Undergraduates' knowledge on SRHR was not in an acceptable level, however their attitudes were positive. Effective educational program should be implemented.

\section{Introduction}

Sexual and Reproductive Health and Rights (SRHR) encompass the right of all individuals to make decisions concerning their sexual activity and reproduction free from discrimination, coercion, and violence. $(1,2)$ SRHR includes that an individual has the right to seek, receive, and impart information related to sexuality; receive sexuality education; respect for bodily integrity; choose their partner; decide to be sexually active or not; has consensual sexual relations; consensual marriage; decide whether or not, and when, to have children; and pursue a satisfying, safe, and pleasurable sexual life. (2) To attain and maintain these rights, all persons must respect, protect and fulfill all human rights. (3)

The concept has been developing since 1994, enshrined in a number of international declarations and agreements. $(1,4)$ SRHR relate to each of the Millennium Development Goals, (5) and they navigate through each of the three dimensions of sustainable development - economic, social and environmental. (6) Therefore it is impossible and unaffordable to leave such rights off, if sustainable development is our end goal.

The right-based approach can be used to prevent risks of sexual and reproductive ill-health including HIV/AIDS, unsafe abortions and maternal motility and to promote sexual and reproductive health. Sexual 
and reproductive ill health accounts for more than a third of the global burden of disease for women of childbearing age, and one-fifth of the burden for the whole population. (7) The implications of protecting SRHR are empowered people, reduced healthcare costs, improved productivity and saves lives which lead to greater economic growth. $(7,8)$ However, SRHR is not yet fully accessible in many parts of the world.(8)

As in other countries teaching of SRHR is not fully integrated into core curricula in Sri Lanka. (9) It is not a part of a university education either, except in the medical curricula. There is no formal system to educate sexual and reproductive rights for the Sri Lankan youth. The Post-2015 Development Agenda has recommended ensuring the access of sexuality education for all girls and boys which is rights-base and extensive. $(10,11)$ The literature on knowledge and attitudes on SRHR among undergraduates are scanty. One study revealed that knowledge and attitudes towards SRHR were low. (12) Another study reported that even though adolescents' awareness on SRR was satisfactory, they did not know about its content. (13) Therefore the objective of this study was to describe the knowledge, attitudes and explore the perceptions regarding SRHR among undergraduates in state universities in Sri Lanka.

\section{Methods}

The study consisted of two components. The component I was a descriptive cross-sectional study which was conducted in four state universities in the Western Province in Sri Lanka from 2013 to 2014. The study population consisted of the undergraduates studying in second and third years of their degree programs. A multistage stratified cluster sampling technique with probability proportionate to size of the student population of each university was carried out to select a representative sample of 1575 undergraduates. A detail of the methodology has been described elsewhere. (14)

A pre-tested self-administrated questionnaire was developed to assess socio-demographic information, knowledge and attitudes on SRHR. The questionnaire included eight statements to assess knowledge and ten statements to assess attitudes on SRHR. One mark was given for each correct answer. All marks were added to obtain a final mark, converted to percentages and then categorized. A score of $>75 \%$ was categorized as good knowledge, $50-74 \%$ as satisfactory and $<50 \%$ as poor knowledge. The questions for assessing attitudes consisted of five responses as strongly agree, agree, neutral, disagree, and strongly disagree. Assessment of attitudes on SRHR was not given scores as the subject is controversial within the Sri Lankan culture.

Knowledge and attitudes on SRHR were expressed as percentages. Associations with good knowledge category with selected variables were assessed with odds ratio (OR) and 95\% confidence interval (Cl). Multiple logistic regression was applied to confirm the association.

The component II. A qualitative study was conducted to explore the perceptions and attitudes on SRHR among undergraduates. The study population consisted of undergraduates studying in second and third year in Faculties of Medicine and Physical Science in the University of Kelaniya. Forty-one undergraduates comprising of 20 females and 21 males participated in four focus group discussions (FGD) with each group having 10-11 members of the same sex. Purposive sampling method was used 
to select the participants based on the availability, enthusiasm and their capability of communication, with the help of university staff.

The study instrument was a focus group discussion guide. Students' perceptions on human rights, SRHR, their perceived barriers and strengths in the protection of those rights and participants' suggestions for improving the services were included as main subheadings. Those subheadings were incorporated into that semi-structured guide using open-ended, non-threatening and non-embarrassing wordings. A research assistant acted as the note-taker and recorder for all FGDs. The selected participants were informed by the moderator around one week prior and the day before the discussion about the date and venue. Their anonymity was ensured. Each group discussion lasted for a duration of around one hour. At end of each session the moderator summarized the key points to the participants and clarified any disputes. All participants were encouraged to talk and every effort was made to facilitate group interactions.

Transcripts were prepared using audio recorded discussions. All transcripts were examined several times and main ideas were noted. Responses that seem to belong to similar categories were listed for particular labels. The final list of labeled categories was coded. The original transcripts were checked again to ensure that all the information need to be categorized has been so. Thematic approach was used for the analysis.

As the FGDs were involved with gender sensitive issues, females and males were separately included into the groups. Discussions were conducted in such times without disturbing their academic work. Informed written consent was obtained from the participants. Ethical clearance was taken from the Ethical Review Committee, Faculty of Medicine, University of Kelaniya.

\section{Results}

\section{Component I}

Majority of the respondents were females ( $n=926,58.8 \%)$ and unmarried $(98.5 \%, n=1551)$. Mean age of the study sample was 23 years $(S D=0.9)$. Of them $516(32.8 \%)$ were art, $424(26.9 \%)$ commerce, 387 (24.6\%) physical sciences and 248 (15.7\%) bio-science students. The undergraduates' understanding of the phrase "sexual and reproductive health rights" is presented in Table 1.

\section{Table 1: Respondents' understanding of "sexual and reproductive health rights"}




\begin{tabular}{lcc}
\hline \multicolumn{1}{c}{ Statement } & Number & Percentage \\
\hline "Rights" to mean entitlement & 978 & 62.1 \\
What belongs to a person & 812 & 51.6 \\
\hline Freedom to do certain things & 558 & 35.4 \\
\hline Privilege had by citizens of a country & 515 & 32.7 \\
\hline Ability to adapt to a situation & 338 & 21.5 \\
\hline Your responsibility & 332 & 21.1 \\
\hline The right in way off sex & 248 & 15.7 \\
\hline Guidance by parents & 120 & 7.6 \\
\hline Fighting for your country & 21 & 1.3 \\
\hline Don't know & 142 & 9.0 \\
\hline
\end{tabular}

Most of the undergraduates (65.1\%) thought that SRHRs are human rights. As the youths, majority of the undergraduates had given positive responses on statements regarding the rights for confidential health services (85.9\%) and the right for services without parental consent $(72.3 \%)$ for youths (Table 2 ).

Table 2: Frequency distribution of correct responses on statements of sexual and reproductive health rights 


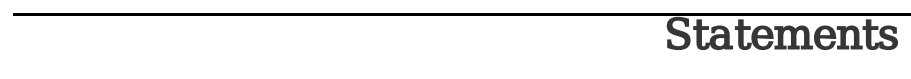

Accurate response No

(\%)

iexual and reproductive health rights are human rights $1025(65.1)$

'ouths have the right that their use of reproductive health services is kept onfidential.

I married woman has the right to limit the number of her children ccording to her desire without her husband's consent.

jirls have the right to resist genital mutilation against their families will

'ouths have a full right to access all reproductive health services without rarents' consent.

jirls have the right to autonomous reproductive choices without their artners consent.

Jnmarried woman have the right to maternity leave with adequate social ecurity benefits. ondoms.

Three hundred and eighty-five (24.4\%) undergraduates had good knowledge, 604 (38.3\%) had satisfactory knowledge and $586(37.2 \%)$ had poor knowledge on SRHR. Males and undergraduates who had studied in bioscience stream had better knowledge than the other categories $(p<0.001)$ (Table 3$)$. These associations remained the same after applying multiple logistic regression.

Table 3: Association between knowledge on sexual and reproductive health rights and selected variables among undergraduates 


\begin{tabular}{|c|c|c|c|c|c|}
\hline \multirow{2}{*}{ Variable } & \multicolumn{4}{|c|}{ Overall knowledge on sexual and $\mathrm{RH}$ rights } & \multirow{2}{*}{$\begin{array}{c}\text { OR } \\
95 \% \text { CI } \\
\text { p value }\end{array}$} \\
\hline & $\begin{array}{l}\text { Good } \\
\text { No }(\%)\end{array}$ & $\begin{array}{c}\text { Satisfactory } \\
\text { No }(\%)\end{array}$ & $\begin{array}{l}\text { Poor } \\
\text { No (\%) }\end{array}$ & $\begin{array}{c}\text { Total } \\
\text { No }(\%)\end{array}$ & \\
\hline Sex $*$ & & & & & 1.52 \\
\hline Male & $187(29.0)$ & 238 (36.9) & $220(34.1)$ & $645(100.0)$ & $1.21-1.92$ \\
\hline Female & $196(21.2)$ & 366 (39.5) & 364 (39.3) & $926(100.0)$ & $p<0.001$ \\
\hline \multicolumn{6}{|l|}{ Study Stream } \\
\hline Bio Science & $83(33.5)$ & 97 (39.1) & $68(27.4)$ & $248(100.0)$ & 1.71 \\
\hline Art & $128(24.8)$ & $223(43.2)$ & $165(32.0)$ & $516(100.0)$ & $1.27-2.29$ \\
\hline Commerce & 85 (20.0) & 151 (35.6) & $188(44.3)$ & $424(100.0)$ & $\mathrm{p}<0.001$ \\
\hline Mathematics & $89(23.0)$ & 133 (34.4) & 165 (42.6) & $387(100.0)$ & \\
\hline \multicolumn{6}{|l|}{ School type** } \\
\hline Mixed & $154(23.9)$ & 243 (37.7) & 248 (38.4) & $645(100.0)$ & 0.88 \\
\hline Boys & 83 (31.7) & 97 (37.0) & $82(31.3)$ & $262(100.0)$ & $0.68-1.14$ \\
\hline Girls & $76(22.0)$ & $129(37.4)$ & $140(40.6)$ & $345(100.0)$ & $\mathrm{p}=0.344$ \\
\hline Total & $385(24.4)$ & $604(38.3)$ & $586(37.2)$ & $1575(100.0$ & \\
\hline
\end{tabular}

OR-odds ratio, CI-confidence interval, $R H$-reproductive health

For application of statistics, poor knowledge and satisfactory knowledge categories were amalgamated as less knowledge. Study streams and school type were also amalgamated to take as binary variables, study streams as Bio Science and non-Bio Science while school type as mixed and non-mixed schools

Regarding attitudes on SRHR, a majority of the undergraduates (93.4\%) agreed with the statement aimed at equal say among both men and women in sexual relationships. Only a very few (3.1\%) thought that the child-care would-be women's sole response. (Table 4).

Table 4: Undergraduates' responses on given statements on attitudes on sexual and reproductive health rights 


\begin{tabular}{|c|c|c|c|}
\hline \multirow[b]{2}{*}{ Statement } & \multicolumn{3}{|c|}{ Attitudes on sexual and RH rights } \\
\hline & $\begin{array}{c}\text { Agree } \\
\text { No (\%) }\end{array}$ & $\begin{array}{l}\text { Neutral } \\
\text { No (\%) }\end{array}$ & $\begin{array}{c}\text { Disagree } \\
\text { No (\%) }\end{array}$ \\
\hline $\begin{array}{l}\text { Men and women should have an equal say in a sexual } \\
\text { relationship. }\end{array}$ & $\begin{array}{l}1463 \\
(93.4)\end{array}$ & $91(5.8)$ & $12(0.8)$ \\
\hline $\begin{array}{l}\text { A man in a relationship has a right to demand sex } \\
\text { whenever he wants from his female partner. }\end{array}$ & $\begin{array}{c}900 \\
(57.5)\end{array}$ & $\begin{array}{c}290 \\
(18.5)\end{array}$ & $376(24.0)$ \\
\hline $\begin{array}{l}\text { A woman has a right to refuse sex with her male } \\
\text { partner anytime she wants. }\end{array}$ & $\begin{array}{c}1234 \\
(78.8)\end{array}$ & $\begin{array}{c}215 \\
(13.7)\end{array}$ & $117(7.5)$ \\
\hline $\begin{array}{l}\text { It is the sole responsibility of a woman to take care } \\
\text { of child or children. }\end{array}$ & $48(3.1)$ & $97(6.2)$ & $\begin{array}{l}1421 \\
(90.7)\end{array}$ \\
\hline Men want more sex than women. & $\begin{array}{c}478 \\
(30.5)\end{array}$ & $\begin{array}{c}815 \\
(52.0)\end{array}$ & $273(17.4)$ \\
\hline $\begin{array}{l}\text { Homosexuality is not acceptable in Sri Lankan } \\
\text { culture }\end{array}$ & $\begin{array}{c}1044 \\
(66.7)\end{array}$ & $\begin{array}{l}246 \\
(15.7)\end{array}$ & $276(17.6)$ \\
\hline There should be law against homosexuality & $\begin{array}{c}809 \\
(51.7)\end{array}$ & $\begin{array}{l}418 \\
(26.7)\end{array}$ & $339(21.6)$ \\
\hline Women should be submissive to men & $511(32.7)$ & $\begin{array}{l}225 \\
(14.4)\end{array}$ & $829(53.0)$ \\
\hline Women should be dependent on men. & $118(7.5)$ & $187(11.9)$ & $1261(80.5)$ \\
\hline Pre-marital sex should be accept in Sri Lanka & $\begin{array}{c}325 \\
(20.8)\end{array}$ & $\begin{array}{c}386 \\
(24.7)\end{array}$ & $854(54.6)$ \\
\hline
\end{tabular}

\section{Component II}

The study sample consisted of 22 medical students and 21 physical science undergraduates. The age range was 21 to 24 years.

\section{Perceptions on human rights and SRHR}

Human rights were identified as the basic rights of humans such as right to live, right to express ideas, right to have education, right to be free from physical and mental harassment. A male medical student further stressed that "we cannot violate our laws even though we have human rights".

SRHR were identified as freedom to engage in sexual activities when a person reaches 18 years of age. Willingness to have sex was considered important. Even though having sex with the other partner was 
claimed as a right owned by husband/wife, consent of the partner was also stressed. A male medical student stated that "Sexual activities are related to producing offspring that should be done according to current rules and regulations and with responsibility". A science student added that SRHR as "a right to act against sexual harassments." Awareness of rights helps not to exceed limits in a relationship. Knowing SRR can also be useful to help those who suffer due to violation of their rights.

A female medical student expressed her view as "it is not a must to agree to a sexual activity even within a marriage. Some women think that it is a must to obey their husbands in sexual activities. There are situations where they suffer mentally and physically. They think that they must do anything to satisfy their husbands". Another female student came up with the idea that "a mother, even if she is unmarried, has a right to protect her fetus without going for an abortion. Even if all the other people are influencing, she can act so if she knows her rights".

\section{Violation of SRHR}

Electronic media especially advertisements and Tele-dramas stimulate the society to violate SRHR rights. For marketing purposes, sexualized images of women are used arousing sexual interest of people. Marriage at a younger age is a major violation observed in some countries. Some cultural/religious beliefs and norms do not allow using contraceptives which lead to violation of SRR. Myths and misbelieves among public such as hymeneal tears and bleeding at first intercourse lead to violation of women's rights.

\section{Strength in our society to protect SRHR}

Marriage is positively influenced by our culture and religion where divorce is much less common. Rights of children are protected by this favorable family condition as both parents look after them until adulthood. "Even for a person without any knowledge, a public health midwife provides education on family planning at home visits" (a Science student). Public awareness is increased through posters, for example on child abuse. Improvement of female education and occupational status was mentioned as a cause to secure females' SRR. Monographs published by Ministry of health and distributed in schools has made a positive impact on reproductive health. Media education programmes also have both negative and positive aspects.

\section{Weaknesses that lead to violation of SRHR}


Most of the participants highlighted that in schools, teaching on SRHR is inadequate. Most often small children undergo sexual abuse due to lack of knowledge. When a small girl is sexually harassed by a known male person, that girl may not think it as an abuse due to unawareness. In the school curriculum, only reproductive systems are discussed at grades eight - nine but not SRHR. Lessons on reproductive health are not taught properly in schools. It was a taboo forbidden lesson where students show less interest in learning while most teachers were reluctant to teach about the same due to embarrassment.

Sex related matters are not talked openly in public, unless it is reported in the news. University students except medical students are not provided with scientific knowledge. Lack of knowledge on family planning has led to increased number of illegal abortions. Few participants expressed the problems faced due to lack of knowledge as follows. "When we attend the clinics for problems related to sex there is no clear guidance or a name board to direct people to the clinics which is a major factor that affects the clinic attendance" (Male Science student)

Several views came up with regard to problems in the law structure. The major points were lack of knowledge on available laws, issues in its enforcement for instance, giving negligible penalties for major offences. Lack of respect for the law among the public may be a reason for violation of SRR.

Enforcement of the law has been unequal for different groups of people such as, politicians. The written down law is not practiced in the real world as expected.

A male medical student expressed his ideas on illegal videos and law in a different manner. "We should talk about laws that protect SRHR of citizens. However, some laws in our country violate those rights. For an example, videos containing sexual acts may provide sex education to some people including married couples even though they can be harmful to the society in general. When the law prohibits these videos, it is a violation of rights of the people who use them for knowledge." The law is not enforced properly. People are not afraid of the law nor do they care about it. Two- or three-year's imprisonment is not considered a major penalty. "Due to this lenient nature of law people take law for granted" another male medical student stated.

Undergraduates from all groups pointed out the issues related to media about SRHR. They talked about Tele-dramas, films, advertisements and the internet, especially social media. Internet uses forceful advertising techniques to promote the internet user to watch sex related videos. Media arouse curiosity of children on sexual issues that leads to risky behaviors. They said most media give wrong images to children. There are lots of wrong teachings in the internet on SRHRs. A similar idea was expressed by a 
female undergraduate "an unacceptable behavior may be perceived as normal due to repeated exposure. Therefore, such acts are accepted as the usual."

Sri Lanka and India as Asian countries have different cultures compared to European countries where things related to sex are not discussed openly and are considered culturally unacceptable. As it is a topic avoided as much as possible in any family conversation, children may rely on outsiders or strangers to obtain knowledge, often leading to negative outcomes and wrong decisions. The close bond between parents and children does not disappear even after reaching adulthood which leads to the adult child having less freedom to take independent decisions which in turn limit their rights. Such children are often shy and have less sex related knowledge. A male science student expressed his views in increasing sexual crimes in Sri Lanka. "In European countries commercial sex, casinos etc. are legalized. There, any interested party has freedom to access those places. However, as such acts are not legalized in Sri Lanka, interested parties may commit crimes to satisfy their needs. It is important to legalize these businesses to cater to their needs."

\section{Suggestions to improve SRHR}

Content related to sexual matters should be included in the school curriculum. Ad-hoc teaching methods should be avoided and subject related questions/discussions should be encouraged in schools. A female science student mentioned "the education should include the culture and the acceptable behavior. If we can cultivate cultural values and acceptable behavior among children the SRR will be secured naturally without any additional effort"

Creating awareness and skills among parents were discussed as important. Ways and means should be established to help parents; especially rural community to acquire skills to detect sex related issues among children and to make them aware that relatives/familiar people may commit such acts. Another expression was that, parents should know the purpose of educating their children on sex related matters.

Knowledge given through media and internet should be closely supervised. Responsible authority should be established to supervise internet/web pages. Education programmes should be age appropriate and delivered at times feasible to most viewers.

Majority claimed that the law should be modified to suit the present situation and penalties for sexual abuses should be severe than the present. A male medical student talked about strengthening the law. "Sexual harassment causes an irreversible damage to the future of the victim. The seriousness of the 
penalty for the perpetrator should carry equal weight. Few years' imprisonment will not be adequate. When the law is flexible, there is less fear for law".

Changes of some cultural and social aspects were proposed by the participants to strengthen the SRRs. Our society should bear positive attitudes towards sexual relationships. Pre-marital sexual relationships are not accepted in our culture. But, an individual's right to have sex should not be violated. Facilities should be provided to prevent unintended pregnancies including availability of family planning methods and freedom to access them without embarrassment, for example to buy condoms or pills from a pharmacy without hesitation.

Children and their guardians should have favorable relationships with each other. Such close relationships may help them to provide education on sexual/reproduction related matters to children at the correct time. Both parents should teach a male child to respect all females from an early age, even if there are no girls in the family. It will minimize violation of sexual rights. If any mother/father sees another person's child as their own, better results can be seen where education alone cannot achieve.

Encouraging spiritual lifestyle benefits the society more than law enforcement. Religious education is important. Dress code of females and fashion trends should match the cultural background of our country to avoid unnecessary harassments.

\section{SRHR among undergraduates within the university}

Even outsiders see the university as a different place with a different sub culture, where close relationships exist between girls and boys. However most of these relationships are not intimate relationships, but they are more platonic in nature. However, educational programmes on SRHR are minimal. Freedom in the university, being away from family, pressure due to education and hormonal changes of youth can lead students to seek wrong sexual relationships. Knowledge on contraceptives is minimal among undergraduates. There are no means of providing knowledge and services with regard to contraceptives inside universities.

\section{Discussion}

\section{Knowledge and attitudes on SRHR}

Good knowledge was reported to be low (24.4\%) for SRR while satisfactory knowledge was slightly higher $(37.3 \%)$ in the current study. In contrast, more than half of the respondents were knowledgeable on SRHR 
as revealed by a study done among undergraduates in an African country. (15) The study(15) determined the cut-off value for good knowledge in relation to the mean of the actual data where we used $75^{\text {th }}$ centile based on the range of the possible score. In addition, the difference between the results of the two studies may be due to the difference in two study populations and due to the different types of questions used for the assessment. Another study reported that mean knowledge score was $3.3+2.9$ on a 20 point scale. (16)

Undergraduates were asked whether a married woman can decide the number of her children without her husband's consent. Less than a quarter agreed with the statement in contrast to $36 \%$ in another study. (15) Only a quarter of the respondents agreed with the statement on girls' right in their autonomous reproductive choices without their partner's consent. It was very low when compared to undergraduates in an African university (46.3\%) Another study reported that $34 \%$ of the respondents agreed that married women have a right to bodily autonomy while $77.3 \%$ rejected the idea that a wife on her own could access family planning services. (15) This discrepancy might be due to differences in culture in the two countries. Majority (62.1\%) of respondents' explanation for "right" was "as an entitlement" of the current study. In contrast, $57 \%$ of out-of-school adolescents in Nigeria referred to rights as entitlements. (13) The majority $(90.7 \%)$ of the respondents disagreed with the statement on sole responsibility of a woman to take care of children. Contrary to that only three quarter of respondents among the undergraduates in the Ethiopian university disagreed with that statement. (15)

\section{Perceptions on SRHR}

Most of the undergraduates were aware of human rights and SRHR. In contrast, only a few identified sexual right as a human right in a study carried out among El-Salvador undergraduates. (17) But adolescents in Ghana were knowledgeable in human and sexual rights.(18)

Identified reasons for rights' violations were lack of knowledge, poor support from law, media, problems related to culture and family environments. In contrast to present findings, another study (17) identified reasons in El-Salvador as socioeconomic issues including poverty, lack of education and gender issues.

Major recommended suggestions for further improvements were sexual education in schools and universities, education and proper implementation of law, and making some changes in social and cultural settings. All these suggestions were described in a Nigerian study among undergraduates. (17) Even-though the lack of sexual education was identified by another study,(17) it was questionable whether the improvement should be in schools or homes. Undergraduates described that their acquiring 
awareness through schools and university curriculum on the above matter is much less. The results were compatible with another study (16) as their major sources of knowledge were mass media, peers, books, etc. Therefore, multidisciplinary and more comprehensive integration of sexual and reproductive health and rights in public health education should be emphasized. (9)

\section{Conclusions}

Undergraduates' knowledge on sexual and reproductive health rights was low, however their attitudes towards rights were positive. Educational programs targeted to undergraduates would be recommended.

\section{Abbreviations}

$\mathrm{Cl}$

Confidence interval

FGD

Focus group discussions

OR

Odds ratio

SRHR

Sexual and Reproductive Health Rights

\section{Declarations}

Ethics approval and consent to participate - Administrative clearance was obtained from the Vice Chancellors and Deans of the selected faculties. Informed written consent was obtained from the participants. Ethical clearance was taken from the Ethical Review Committee, Faculty of Medicine, University of Kelaniya.

Consent for publications- Not applicable

Availability of data and materials- Data and materials are available with the authors.

Competing interests - The authors declare that they have no competing interests.

Funding- Conduction of the study was funded by the ministry of Health, Medical Research Institute, Sri Lanka

Authors' contributions - Both authors have contributed equally to the design the study. UP and CA analyzed and interpreted the data. UP was responsible for the conduct of the literature review and implementation of study and a major contributor in writing the manuscript. All authors read and approved the final manuscript. 
Acknowledgements - All the undergraduates who participated for the study and the staff of the Universities, data collectors and the members of the Board of Study in Community Medicine, Postgraduate Institution of Medicine.

\section{References}

1. Report of the International Conference on Population and Development. New York: United Nations publication. Sales no.95.XIII.181995.

2. World Health Organization, Defining Sexual Health: Report of a Technical Consultation on Sexual Health (Geneva: WHO, 2006), 5.

3. Leary VA: The right to health in international human rights law. Health Hum Rights 1994, 1:24-56.

4. ICPD Beyond 2014. International Conference on Human Rights. July 2013. http://humanrights.icpdbeyond2014.org.

5. Population Action International: The Key to Achieving the Millennium Development Goals: Universal Access to Family Planning and Reproductive Health. Washington: Population Action International; 2010. https://pai.org/wp-content/uploads/2012/01/PAI-MDG-brief.pdf.

6. International Planned Parenthood Federation. Sexual and reproductive health and rights: A crucial agenda for the post-2015 framework. 2014.

7. DFID. Sexual and reproductive health and rights A position paper. Department for International Development. 2004. http://www.hivpolicy.org/Library/HPP000499.pdf

8. Family Care International. Briefing Cards: Sexual and Reproductive Health and Rights (SRHR) and the Post-2015 Development Agenda. http://www.unfoundation.org/what-we-do/campaigns-andinitiatives/universal-access-project/briefing-cards-srhr.pdf.

9. Pascale A A, Simone D, Jocelyn D, Thérèse D, Sofia G, Sharon F. Sexual and reproductive health and rights in public health education, Reproductive Health Matters, 2011;19:38, 56-68, DOI:

10.1016/S0968-8080(11)38577-1

10. United Nations Conference on Sustainable Development, Rio + 20. 2012. https://sustainabledevelopment.un.org/rio20.html.

11. International technical guidance on sexuality education An evidence-informed approach. Second edition. UNESCO, 2018. http://creativecommons.org/licenses/by-nc-nd/3.0/igo/

12. Chiedza M, Faith K. Knowledge, Attitudes and Practices of Students towards Their Sexual and Reproductive Health Rights in Tertiary Institutions: A Case Study of Bulawayo Polytechnic, International Journal of Innovative Research \& Development. 2016;5(1):231-242.

13. Ogunlayi MA. An Assessment of the Awareness of Sexual and Reproductive Rights among Adolescents in South Western Nigeria, African Journal of Reproductive Health; 2005;9(1): 99-112.

14. Perera $U$, Abeysena $C$. Prevalence and associated factors of risky sexual behaviors among undergraduate students in state universities of Western Province in Sri Lanka: a descriptive cross sectional study. Reproductive Health. 2018;15:105. https://doi.org/10.1186/s12978-018-0546-z 
15. Adinew YM, Worku AG, Mengesha ZB. Knowledge of reproductive and sexual rights among University students in Ethiopia: Institution-based cross-sectional, BMC International Health and Human Rights. 2013;13:12

16. Egemba MN, Ajuwon AJ. Knowledge and Perceptions of Reproductive Rights among Female Postgraduate Students of the University of Ibadan, Nigeria. Afr. J. Biomed. Res. 2015;18:95-107.

17. Ekdahl A. A qualitative study about Sexual and Reproductive Health and Rights focusing in contraceptives and abortion among university students in El Salvador. 2009. https://gupea.ub.gu.se/bitstream/2077/20419/1/gupea_2077_20419_1.pdf

18. Yendaw E, Martin-Yeboah E, Bagah D. Knowledge and Perception of Adolescents on Sexual and Reproductive Health Rights in Ghana: A Case Study of Yamoransa in the Mfantseman Municipality. British Journal of Education, Society \& Behavioural Science. 2015;8(3): 147-158, 2015, 